\title{
Height-Based Formula Predicting Renal Length in Korean Children derived from Technesium-99m Dimercaptosuccinic Acid Scan
}

\section{Myung Hyun Cho, M.D. ${ }^{1}$, Ha Yeong Yoo, M.D. ${ }^{1}$, Byung Ok Kwak, M.D. ', Hye Won Park, M.D. ', Sochung Chung, M.D.', Soo Nyung Kim, M.D.', Jae Sung Son, M.D. ${ }^{1}$, Kyo sun Kim, M.D. ${ }^{1}$}

Departments of ${ }^{1}$ Pediatrics and ${ }^{2}$ Obsterics and Gynecology, Konkuk University Medical Center, Konkuk University School of Medicine, Seoul, Korea

Corresponding author: Kyo Sun Kim, M.D., Ph.D.

Department of Pediatrics, Konkuk University

Medical Center, 120-1 Neungdong-ro,

Gwangjin-gu, Seoul 143-729, Korea

Tel: +82-2-2030-7370

Fax: +82-2-2030- 7748

E-mail:19890009@kuh.ac.kr

Received: 6 August 2015

Revised: 31 August 2015

Accepted: 14 September 2015

This is an open-access article distributed under the terms of the Creative Commons Attribution Non-Commercial License (http:// creativecommons.org/licenses/bync/3.0/) which permits unrestricted non-commercial use, distribution, and reproduction in any medium, provided the original work is properly cited.
Purpose: The aim of this study was to establish a simple formula to predict renal length in children using a Technesium-99m dimercaptosuccinic acid (DMSA) scan data, and to compare it with the formula derived from ultrasonography, which is widely accepted.

Methods: Children who underwent a DMSA scan and ultrasonography were reviewed retrospectively, and those who had anatomical urinary tract abnormalities or urinary tract infections were excluded.

Results: A total of 230 children (84 males and 146 females; age, 1 month to 16 years; mean age, $16.8 \pm 27.4$ months). Mean renal length measured by DMSA scan was longer than that by ultrasonography $(6.38 \pm 1.16$ vs. $6.02 \pm 1.14 \mathrm{~cm} ; P<0.001)$. Renal length was correlated with age, weight, height, and body surface area on the DMSA scan and ultrasonography, and showed the strongest positive correlation with height. The following formulae were established to predict renal length: mean renal length $(\mathrm{cm})=5.433 \times$ height $(\mathrm{m})+2.330(\mathrm{R} 2,0.833)$ using the DMSA scan data, and mean renal length $(\mathrm{cm})=5.367 \times$ height $(\mathrm{m})+2.027(\mathrm{R} 2$, 0.853) using ultrasonography data.

Conclusion: We propose a simple height-based formula to predict renal length in children using a DMSA scan data, and validate it by comparing with ultrasonography formula.

Key words: Kidney, Organ size, Technesium Tc 99m dimercaptosuccinic acid, Ultrasonography, Child

\section{Introduction}

Kidney size is an important parameter for evaluating renal diseases, as many renal diseases are associated with changes in kidney size ${ }^{1,2)}$. Therefore, references for ideal kidney size in children whose organs grow rapidly are valuable. Some reports have predicted ideal renal length using the simple age-based equation from ultrasonography-derived data ${ }^{3)}$. Ultrasonography is an invaluable tool in nephrology and is the most widely used method of measuring renal length in practice. Besides ultrasonography, there are several imaging modalities which provide renal length measurements. The technesium-99m dimercaptosuccinic acid (DMSA) scan, which is widely 
used to evaluate genitourinary abnormalities and function, provides more accurate renal length ${ }^{4}$. Renal length value measured by DMSA scan may not satisfy the formula obtained by ultrasonography data since the renal length measured by DMSA scan exceeded that measured by ultrasonography $y^{5)}$. However little has been reported about renal length using DMSA scans in children ${ }^{5-8)}$.

In previous study, we established age-based formula for estimating renal length using DMSA scan data in children, but found that renal length was poorly estimated by a simple age-based formula in infants younger than 1 year of age ${ }^{7}$. In the present study, we evaluated the relationships between several anthropometric indices and renal length measured by DMSA scan, and established a simple, exact formula to predict renal length in children of all ages in relation to height, the best correlated anthropometric index. Then, we built another predictive formula using ultrasonography measurements data which was collected in the same population, and compared it with the DMSA scan formula.

\section{Materials and methods}

\section{Subjects}

A retrospective study was undertaken of all children < 18 years of age who underwent both a DMSA scan and renal ultrasonography at Konkuk University Medical Center from June 2006 to October 2013. They visited the hospital with impression of urinary tract infection. Their urine samples were collected, and then they were performed both imaging tests. Patients whose initial urine culture tested negative unexpectedly were included. Patients with renal abnormalities on imaging, including hydronephrosis, vesicoureteral reflux, ureteropelvic junction obstruction, polycystic kidney disease, multicystic dysplastic kidney, solitary kidney, or cortical scarring were excluded. Age, sex, height, and weight were collected by reviewing the patient's medical records.

This study was approved by the Institutional Review Board of Konkuk University Medical Center, Seoul, Korea (IRB No. KUH1090032).

\section{Renal length measurements using a DMSA scan and ultrasonography}

Ultrasonographic examinations were performed using an iU22 ultrasound unit (Philips Ultrasound, Bothell, WA, USA) with a 5-8 or 1-5 MHz convex transducer. Children were examined in a supine position with breathholding, if possible. Radiologists obtained separate longitudinal views of each kidney and achieved the maximum longitudinal axis manually. Renal length was measured using electronic calipers on the scan.

The DMSA scans were performed on Siemens e.Cam Single Systems scanner equipped with a high resolution collimator. All children received a weight-adjusted dose of technesium-99m intravenously (approximately 7.4 MBq/10 $\mathrm{kg}$ ), and they were imaged at least 3 hours after injection. Measurements were performed for each kidney. The tips of the superior and inferior poles of each kidney were defined manually based in a visual inspection of the images. The pixel distance between these two points was calculated and converted to $\mathrm{cm}$ using a calibration factor determined for the gamma camera.

\section{Statistical data analysis}

Statistical analyses were performed using PASW ver. 18.0 (SPSS Inc., Chicago, IL, USA) and dBSTAT ver. 5 (dBSTAT Software, Seoul, Korea). The paired t-test was used to compare the length of bilateral kidneys and to compare the measured renal lengths between the DMSA scans and ultrasonography. Relationships between the anthropometric indices and renal length were detected using Pearson's correlation and linear regression analyses. A best-fit line was created based on the assumption of a linear relationship and the coefficient of determination $\left(R^{2}\right)$. The formula to predict renal length for age $\geq 1$ year was compared with the formula for age $<1$ year using analysis of covariance. A $P$-value $<0.05$ was considered to indicate significance.

\section{Results}

A total of 230 children (84 [37\%] males and 146 [63\%] females) met the inclusion criteria for this study. Their mean age was $16.8 \pm 27.4$ months (range, 1 month to 16 years). The mean height was $0.74 \pm 0.19 \mathrm{~m}$, and the mean weight was $10.09 \pm 7.11 \mathrm{~kg}$. The mean body surface area 
Table 1. Discrepancy in renal length between Technesium-99m dimercaptosuccinic acid (DMSA) scan and ultrasonography.

\begin{tabular}{llc}
\hline & DMSA scan & Ultrasonography \\
\hline Left renal length $(\mathrm{cm})$ & $6.45 \pm 1.23^{*}$ & $6.11 \pm 1.18$ \\
Right renal length $(\mathrm{cm})$ & $6.30 \pm 1.14^{*}$ & $5.94 \pm 1.14$ \\
Mean renal length $(\mathrm{cm})$ & $6.38 \pm 1.16^{*}$ & $6.02 \pm 1.14$ \\
\hline
\end{tabular}

Values are means \pm standard deviation.

${ }^{*} P<0.001$ in renal length between DMSA scan and ultrasonography.

Table 2. Correlation coefficients between renal length and age, weight, height, and body surface area (BSA) using the two methods.

\begin{tabular}{lcc}
\hline Variable & Renal length with DMSA scan & Renal length with ultrasonography \\
\hline Age (months) & 0.856 & 0.884 \\
Weight (kg) & 0.862 & 0.874 \\
Height $(\mathrm{cm})$ & 0.913 & 0.924 \\
BSA $\left(\mathrm{m}^{2}\right)$ & 0.902 & 0.915 \\
\hline$P<0$. & & \\
\hline
\end{tabular}

$P<0.001$ in all indices

A

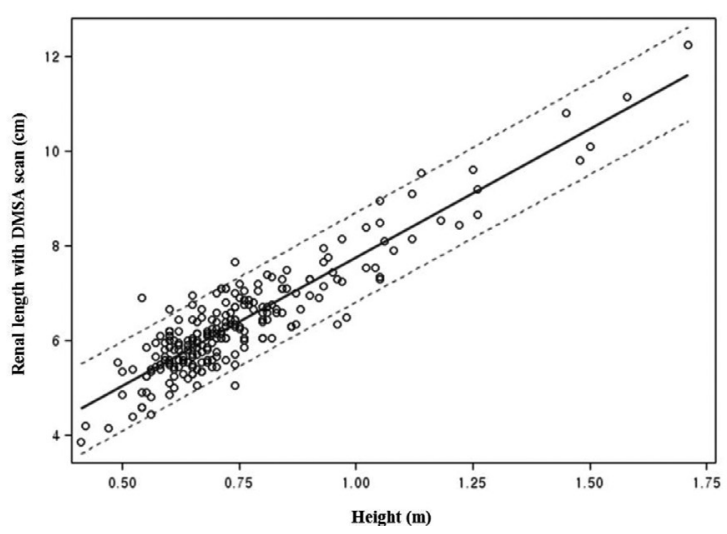

B

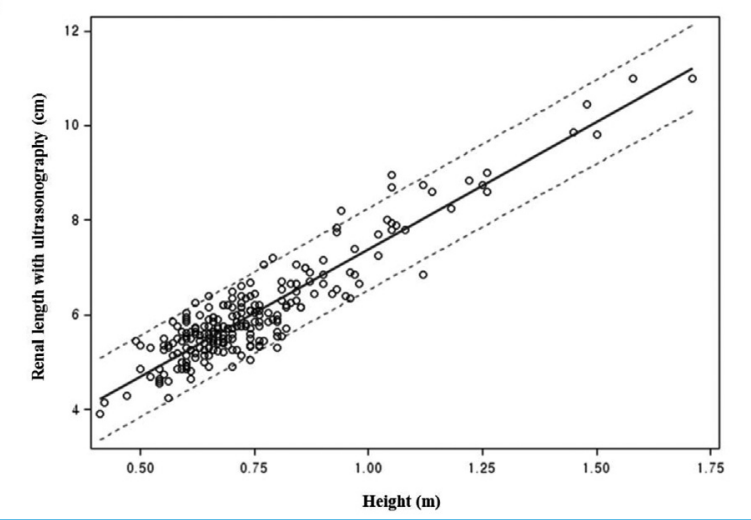

Fig. 1. Scatter plots and linear regression lines for height and renal length using (A) Technesium-99m dimercaptosuccinic acid (DMSA) scan and (B) ultrasonography data, including the range for the estimated 95\% prediction limit. (A) Renal length using the DMSA scan data. Mean renal length $(\mathrm{cm})=5.433 \times$ height $(\mathrm{m})+2.330\left(\mathrm{R}^{2}, 0.833\right)$. (B) Renal length using ultrasonography data. Mean renal length $(\mathrm{cm})$ $=5.367 \times$ height $(m)+2.027\left(R^{2}, 0.853\right)$.

(BSA) was $0.44 \pm 0.21 \mathrm{~m}^{2}$.

The mean renal length measured by DMSA scan was longer than that measured by ultrasonography $(6.38 \pm 1.16$ vs. $6.02 \pm 1.14 \mathrm{~cm} ; P<0.001)$. The left kidney was longer than the right kidney in both methods (DMSA scan: 6.45 \pm 1.23 vs. $6.30 \pm 1.14 \mathrm{~cm} ; P<0.001$; ultrasonography: $6.11 \pm$ 1.18 vs. $5.94 \pm 1.14 \mathrm{~cm} ; P<0.001$ ) (Table 1). No difference in renal length was observed between the sexes after adjusting for height. Table 2 shows the correlations between mean renal length and age, weight, height, and BSA. All indices were correlated with renal length $\left(R^{2}\right.$ s $\left.>0.8\right)$, and height had the highest correlation coefficient in both methods. The mean renal lengths measured by DMSA scan and ultrasonography were plotted against height including the estimated 95\% prediction limit (Fig. 1). The scatter plots show a nearly linear correlation between renal length and height. The best-fit lines in the simple linear regression model were calculated (Fig. 2).

Mean renal length $(\mathrm{cm})$ measured by DMSA scan $=$ $5.433 \times$ height $(\mathrm{m})+2.330\left(\mathrm{R}^{2}=0.833\right)$ Mean renal length $(\mathrm{cm})$ measured by ultrasonography $=5.367 \times$ height $(\mathrm{m})+$ $2.027\left(\mathrm{R}^{2}=0.853\right)$.

\section{Discussion}

In spite of the fact that DMSA scan provides accurate renal length, little has been reported about renal length using $\mathrm{it}^{5-8)}$. We evaluated the association of renal length measured by DMSA scan and anthropometric indices, 


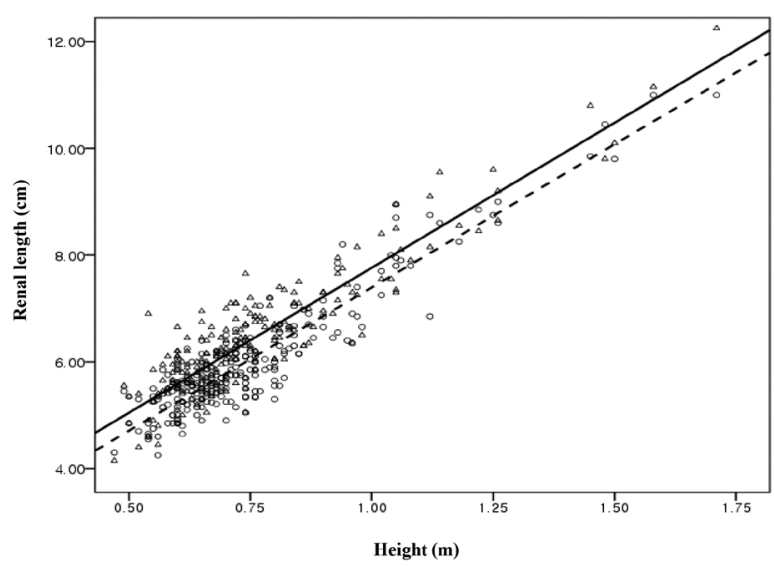

Fig. 2. Comparison between formula to predict renal length from Technesium-99m dimercaptosuccinic acid (DMSA)-derived data and that from ultrasonography-derived data. Solid line represents DMSA scan formula, and the dashed line represents the ultrasonography formula. Each triangular dot represents mean renal length measured by a DMSA scan and round dot represents that by ultrasonography.

and proposed a height-based formula to predict renal length in children. We also built the ultrasonography formula from the same population, and compared it with the DMSA scan formula. Predictors of two formulae were similarly high. Renal length calculated with the DMSA scan formula exceeded that calculated with ultrasonography formula by approximately $0.369 \mathrm{~cm}$ if height was $1 \mathrm{~m}$. The difference was little changed even if the height was changed.

Kidney size is an important parameter for diagnosing, treating, and predicting the prognosis of kidney disease in children ${ }^{1)}$. Thus, a reliable reference for normal kidney size in children is valuable. Kidney size can be estimated by measuring renal length or renal volume. Renal volume theoretically represents renal size but renal length is commonly measured to evaluate kidney size because of its simplicity. Renal length is eligible as the standard parameter for kidney size because it correlates well with renal volume9).

Renal length measurements are obtained using several imaging modalities, including ultrasonography, computed tomography, magnetic resonance imaging, intravenous urography, and DMSA scans. Ultrasonography is an invaluable tool for imaging kidneys because the renal cortex, medulla, and collecting system have different acoustic properties, and pathological changes are easily discernible ${ }^{1)}$. Moreover, it is safe, simple, and inexpensive. However, it has accuracy and reproducibility problems ${ }^{10}$.
Many factors, including examiner skill, patient cooperation, and additional outside factors, adversely influence the accuracy and reproducibility of ultrasonography ${ }^{10)}$. The DMSA scan, which is widely used to evaluate genitourinary abnormalities and function in clinical practice, provides more accurate renal length than ultrasonography. In an animal pathological study ultrasonography measurements were a mean of $22 \%$ lower than the actual pathological-determined size ${ }^{4)}$. While DMSA scan measurements were a mean of $6 \%$ higher than the actual pathologicaldetermined size. Considering the reduction in kidney volume due to loss of blood after autopsy, DMSA scan measurements may be more accurate in vivo. Ultrasonography underestimates renal length, because it is difficult to obtain the maximum longitudinal axis reliably ${ }^{4)}$. Moreover, interobserver reproducibility for DMSA scans is at least as good as that of ultrasonography. The mean difference in renal length ultrasonography measurements between two imagers ranges from $3.87 \pm 2.39$ to $5.49 \pm 3.27 \mathrm{~mm}$, which corresponds to $2-3$ years of renal growth during childhood ${ }^{11}$. The mean difference between two observer's DMSA scan measurements was $2.0 \pm 4.8 \mathrm{~mm}^{12}$.

In this study, renal length measured by DMSA scan was longer than that by ultrasonography, as in a previous animal study ${ }^{4}$. The left kidney was longer than the right with both measurement methods. The different shapes of the bilateral kidneys make different lengths. The left kidney is slimmer than the right ${ }^{13)}$. Whether renal length is different between boys and girls is controversial ${ }^{3,14,15)}$; however, we found no difference after adjusting for height in this study. Fever did not affect DMSA scan measurement. There was no difference of the renal length measured by DMSA scan after adjusting for height between febrile group and afebrile group ( $6.51 \pm 0.08$ vs. $6.36 \pm 0.03 \mathrm{~cm} ; P=0.086$ ).

Renal length is correlated with age, height, weight, and $\mathrm{BSA}^{3,14,16)}$. Age is convenient and has been used as a variable in previous univariate equations ${ }^{3,6,7}$. However, it is difficult to predict renal length in all ages with a single age-based formula since kidney grows fast during the first year of life ${ }^{3,7)}$. Previous formulae based on age were applied to children $>1$ year, but they were not applicable to infants ${ }^{3,7)}$. We used height as a single variable to establish the formula. Height is theoretically reliable as a single variable because both height and kidneys grow in the same rapid pattern 
during very young childhood. In this study, height correlated the best with renal length and showed a nearly direct linear relationship on a scatter plot with both methods. To verify that our height-based formula predicts renal length in all children, from a few months of age till adolescence, we divided the children at the age of 1 year and built two formulae. In children $<1$ year old, the formula was mean renal length $(\mathrm{cm})$ measured by DMSA scan $=5.314 \times$ height $(\mathrm{m})+2.393\left(\mathrm{R}^{2}=0.446\right)$, and $5.272 \times$ height $(\mathrm{m})+$ $2.513\left(\mathrm{R}^{2}=0.840\right)$ in children $\geq 1$ year old. The two slopes are then compared using analysis of covariance. The results show that the two slopes are not significantly different $(P=0.352)$.

This study had some limitations. We had an uneven age distribution in the enrolled population. Children $<1$ year old comprised $69 \%$ of the study population. More studies for preschool children and adolescents are necessary to validate the application of our formula to all age children. This study was retrospective, which was a limitation. In addition, although we attempted to exclude patients with abnormal kidneys, there was a selection bias because the data were obtained from children suspicious of renal disease.

In conclusion, we established a simple, height-based formula to predict ideal renal length in Korean children using DMSA scan derived data, and compared it with an ultrasonography formula. We propose that this equation will be useful to estimate adequate renal growth.

\section{Conflicts of interest}

No conflict of interest exists in relation to submitted manuscript, and there was no source of funding.

\section{References}

1. O'Neill WC. Sonographic evaluation of renal failure. Am J Kidney Dis 2000;35:1021-38.

2. Moghazi S, Jones E, Schroepple J, Arya K, McClellan W, Hennigar
RA, et al. Correlation of renal histopathology with sonographic findings. Kidney Int 2005;67:1515-20.

3. Akhavan A, Brajtbord JS, McLeod DJ, Kabarriti AE, Rosenberg HK, Stock JA. Simple, age-based formula for predicting renal length in children. Urology 2011;78:405-10.

4. Rossleigh MA, Farnsworth RH, Leighton DM, Yong JL, Rose M, Christian CL. Technetium-99m dimercaptosuccinic acid scintigraphy studies of renal cortical scarring and renal length. J Nucl Med 1998;39:1280-5.

5. Sisayan RM, Rossleigh MA, Mackey DW. Nomograms of renal length in children obtained from DMSA scintigraphy. Clin Nucl Med 1993;18:970-3.

6. Lobo Sotomayor G, Ladron de Guevara Hernandez D, Arnello Viveros F, Perez Rivera A, Jimenez Jorquera C. Renal size in children with normal renal 99mTc-DMSA scan: Building a nomogram with scintigraphic length. Rev Esp Med Nucl 2004;23:102-5.

7. Lee MJ, Son MK, Kwak BO, Park HW, Chung S, Kim KS. Kidney size estimation in korean children with technesium-99m dimercaptosuccinic acid scintigraphy. Korean J Pediatr 2014;57:41-5.

8. Kim BW, Song MK, Chung S, Kim KS. Evaluation of kidney size in children: A pilot study of renal length as a surrogate of organ growth. Korean J Pediatr 2012;55:54-7.

9. Emamian SA, Nielsen MB, Pedersen JF, Ytte L. Kidney dimensions at sonography: Correlation with age, sex, and habitus in 665 adult volunteers. AJR Am J Roentgenol 1993;160:83-6.

10. Zerin JM, Blane CE. Sonographic assessment of renal length in children: A reappraisal. Pediatr Radiol 1994;24:101-6.

11. Schlesinger AE, Hernandez RJ, Zerin JM, Marks TI, Kelsch RC. Interobserver and intraobserver variations in sonographic renal length measurements in children. AJR Am J Roentgenol 1991;156:1029-32.

12. Lin E, Connolly LP, Zurakowski D, DiCanzio J, Drubach L, Mitchell $\mathrm{K}$, et al. Reproducibility of renal length measurements with 99mTc-DMSA SPECT. J Nucl Med 2000;41:1632-5.

13. Schmidt IM, Main KM, Damgaard IN, Mau C, Haavisto AM, Chellakooty M, et al. Kidney growth in 717 healthy children aged 0-18 months: A longitudinal cohort study. Pediatr Nephrol 2004;19:992-1003.

14. Han BK, Babcock DS. Sonographic measurements and appearance of normal kidneys in children. AJR Am J Roentgenol 1985;145:611-6.

15. Chen JJ, Pugach J, Patel M, Luisiri A, Steinhardt GF. The renal length nomogram: Multivariable approach. J Urol 2002;168:2149-52.

16. Kim JH, Kim MJ, Lim SH, Kim J, Lee MJ. Length and volume of morphologically normal kidneys in korean children: Ultrasound measurement and estimation using body size. Korean J Radiol 2013;14:677-82. 